Agricultural

Marketing

Service

December 2019

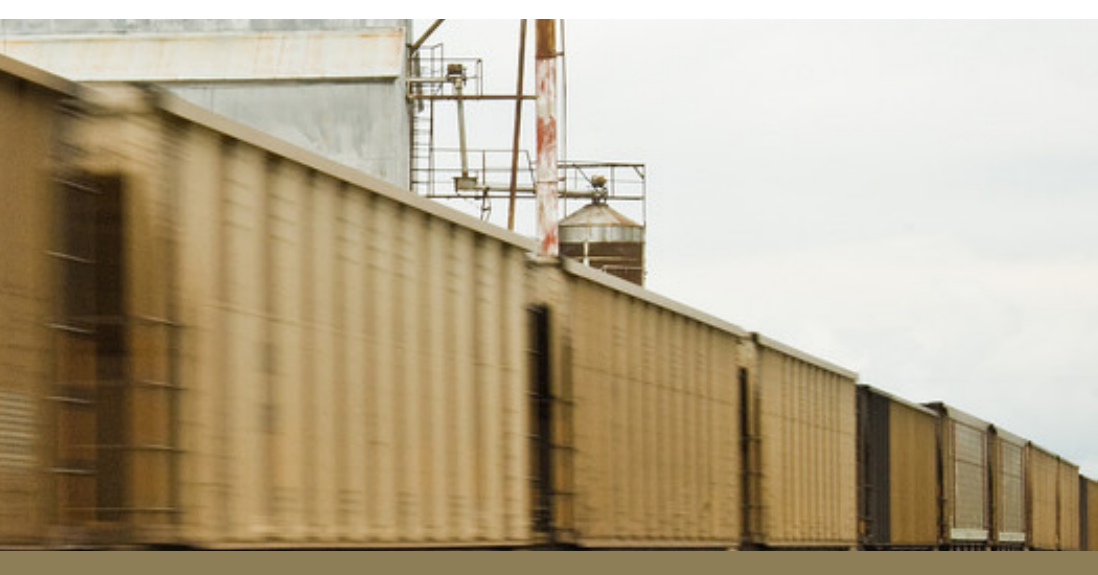

Barge Traffic Disruptions and Their Effects on Shipping Costs in Agricultural Freight Corridors (Summary)

This is a summary of "Barge Traffic Disruptions and Their Effects on Shipping Costs in Agricultural Freight Corridors" by Mark Burton at University of Tennessee - Knoxville. Funding for this paper came from the Agricultural Market Service (AMS) through cooperative agreement number 17-TMTSD-TN-0009. The full paper is available at: https://ctr.utk.edu/CTR-research/Ag-Freight-Corridors-Burton-Sept2019-Final.pdf.

\title{
WHAT IS THE ISSUE?
}

Efficient transportation of grains and soybeans is important to U.S. competitiveness in the global agricultural market. Large volumes of grain, soybeans, and other commodities are shipped using the inland waterways system, which offers lower transportation costs than rail shipping for grain destined for export at central Gulf ports. Given U.S. dependence on the inland waterways system, unplanned disruptions to it can impede the movement of these goods to domestic and export locations. Previous studies have examined the competition between barge and rail service, focusing on the effect the availability of waterway shipping has on rates and market structure in the rail industry. This report explicitly investigates the effect on shipper costs and rail traffic that would be associated with partial or total absence of barge services.

Grains produced in the upper Mississippi and Illinois River basins rely on a complex and competitive relationship between barge and railroad transportation to reach export markets in the Louisiana Gulf. However, it is unclear what the effect would be if the rail network were to accommodate a large and rapid increase in grain diverted from barge transportation due to disruptions to the inland waterways system. This study provides an extensive analysis of two hypothetical scenarios of navigation failure on the inland waterways and their effects on grain transportation by barge and rail.

The movement of farm products from the upper Mississippi and Illinois River basins to export locations throughout the U.S. exemplifies a challenge that inheres in all freight transportation. Competitiveness in global agricultural markets depends on the efficient domestic transportation of agricultural goods. However, developing and operating freight networks that yield low transport costs can also mean sacrificing flexibility and resilience-two qualities that are also vital to agricultural producers. Farm products must move affordably, 
but the freight networks for transporting them must also be dependable and able to accommodate rapidly changing demands. Ultimately, there is a tradeoff between cost-reducing transportation strategies and those designed to ensure a robust and responsive freight network.

The primary goal of this analysis is to understand the consequences of a major disruption at two networkcritical locations on the inland waterways. Specifically, this analysis looks at the ability of the inland waterways and rail network to absorb displaced traffic by alternate truck-to-barge routes, rail-to-barge routes, or rail-allthe-way routes and how these alternate routings affect transportation pricing.

\section{HOW WAS THE REPORT CONDUCTED?}

This report considers the effect of a disruption to either of two lock facilities used in waterborne transportation of grain destined for the Gulf coast, (1) the LaGrange Lock and Dam on the Illinois River and (2) Lock and Dam 25 on the Mississippi, immediately above St. Louis. Each of these lock and dam facilities is critical to maintaining agricultural traffic on a length of a major waterway. Both facilities were completed in 1939, and their age puts them at an increased risk of failure. A disruption at LaGrange would make it impossible for most waterway grain shippers on the Illinois River to reach the Gulf or for up-bound fertilizer to reach the Illinois basin, but it would not affect the ability to ship on the upper Mississippi River. Likewise, an outage at Lock and Dam 25 would make it impossible for Mississippi River shippers above St. Louis to reach the Gulf by barge, but navigation on the Illinois River would still be possible.

\section{Closure Scenario, Lock \& Dam 25}

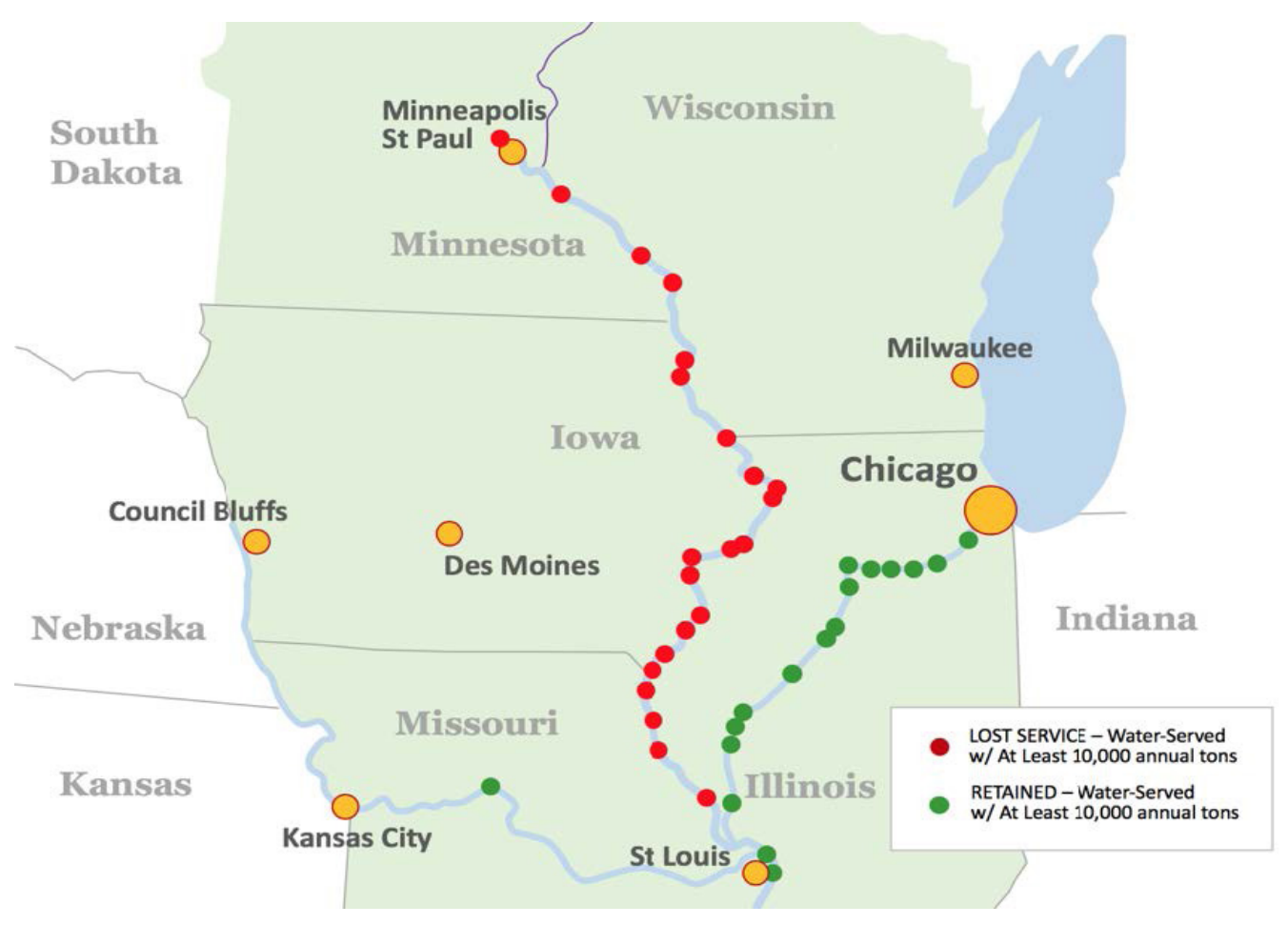




\section{Closure Scenario, LaGrange Lock \& Dam}

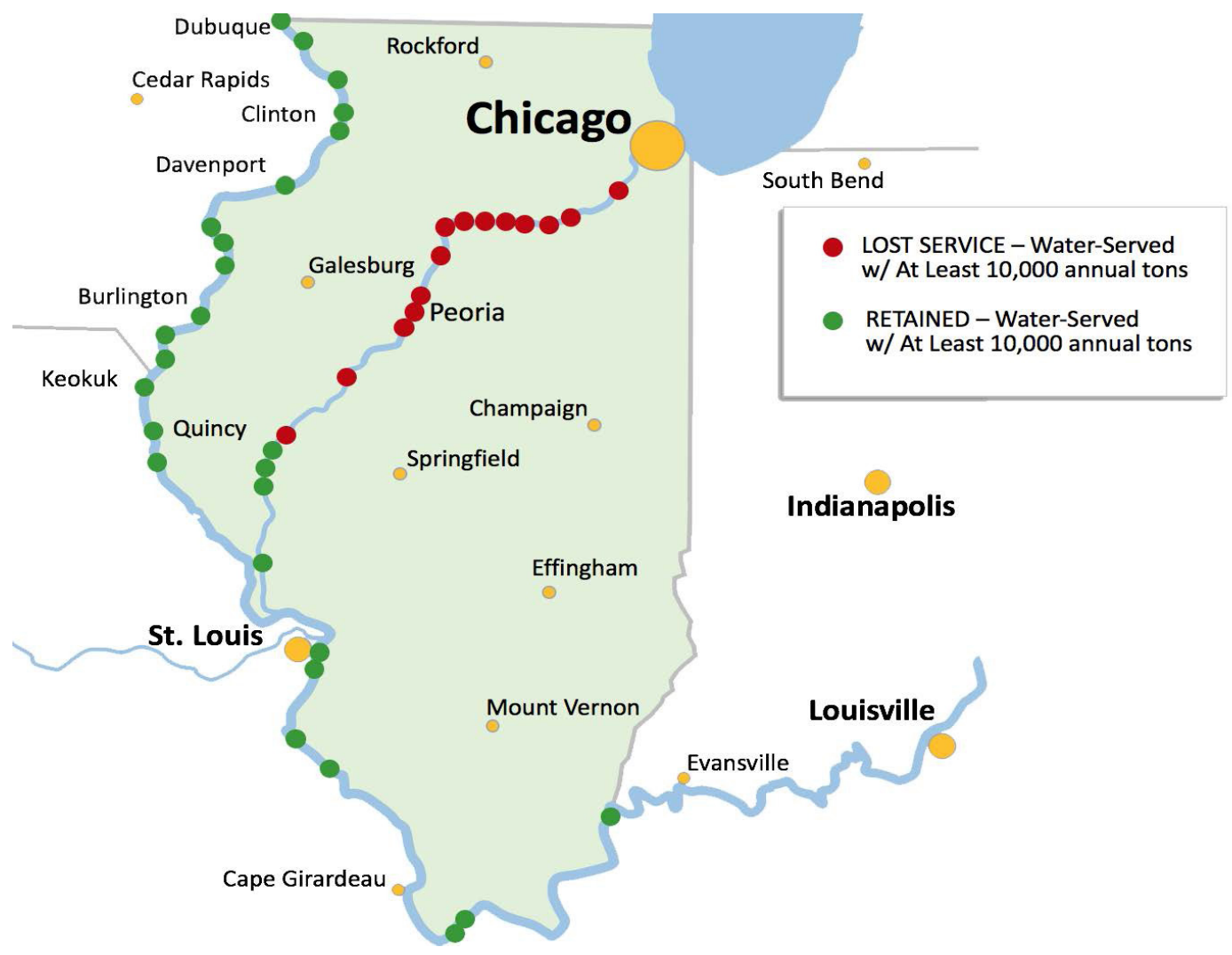

The study authors evaluate the feasibility and cost of these disruptions using several transportation datasets. Barge data from the U.S. Army's Waterborne Commerce Statistics Center are used to create three models of the typical flow of down-bound traffic of agricultural commodities and up-bound traffic of fertilizer between the two study regions and the Louisiana Gulf. Using data from 1999 to 2017, the first model represents traffic flows during an average year in that period. The second model represents traffic flows during 2017 (the last year of data), and the third model represents the maximum observed traffic flows of the period (1999 for Lock and Dam 25; 2002 for LaGrange).

Rail data from the U.S. Surface Transportation Board's Carload Waybill Sample are combined with RAILNET, a GIS-based rail routing platform developed at the University of Tennessee, to model rail routings and traffic volumes in response to the different barge scenarios. RAILNET uses a set of computational programs to realistically route rail traffic by minimizing system transportation costs.

For each of the three traffic flow models, the analysis assumes an unscheduled 12-month closure at both locks to simulate a temporary but significant disruption to the inland waterways to measure the volume of displaced agricultural barge traffic. Furthermore, displaced barge traffic is assumed to seek alternate waterways accessto the extent there is excess terminal capacity along the waterways-before seeking rail access. The rail industry is assumed not to make significant investment in new network capacity to alleviate the temporary disruption on the inland waterways. The authors estimate the cost associated with increased truck miles by using the closest operational rail or barge facility. 
The simulations and computations have determined that there would be significant cost increases associated from partial or complete loss of barge service in portions of the Mississippi and Illinois basins. These cost increases would be driven by increased shipping rates and travel miles for the commodities.

In an average year, a 12-month disruption to the LaGrange Lock and Dam would displace 12.4 million tons of grain. However, given the availability of alternative origin points for barge shipping, shippers could continue using barge shipments for the majority or all of these shipments, with increased trucking cost based on greater distance to these active barge terminals. If shippers were able to use alternative origins for barge shipment, the increase in cost associated with trucking the cargo to these new locations would total nearly $\$ 23$ million in an average year. In a high-traffic year such as 2017, the cost increase to shippers could be over \$265 million, with rail absorbing 1.5 million tons of grain that was beyond the capacity of the barge terminals. In an extreme scenario where no alternative means of using barge existed, the cost increase due to rail-only shipping and other ancillary costs would total over $\$ 895$ million.

A 12-month disruption to Lock and Dam 25 would result in a diversion of 18.5 million tons of grain. Because of the lack of nearby alternative barge terminals still in operation, there would be a greater need for rail services to compensate for the loss of waterborne traffic. Of the 18.5 million tons, 9.5 million tons would need to use rail. However, if the diverted traffic equaled the amount shipped via barge in 1999, up to 28.5 million tons of grain would need to be routed using rail. Using 2017 traffic levels, the cost increase would be nearly $\$ 947$ million. If there were no barge option, the cost increase would be nearly $\$ 1.8$ billion.

The authors' approach is conservative in several respects. It does not model the increase in rail or truck rates associated with the rise in demand that would result if barge traffic were disrupted at these locations. The authors' simulations also allow for highly flexible deployment of personnel and equipment. Realistically, it may be more difficult for grain to be rerouted to rail because of capacity constraints, particularly in the availability of train crews, who must be trained and certified to operate on specific routes. The trend in rail operations has been toward lean, efficient service with little excess capacity or operational flexibility. It is unlikely that rail routes and services will be expanded in response to transient increases in demand for rail service in the affected areas.

\section{CONCLUSIONS}

The findings suggest that a well-functioning lock and dam system in the inland waterways is crucial to maintaining low-cost grain shipments in the Mississippi and Illinois River basins. Disruption to these waterways will result in significantly higher costs for shippers and the potential for reduced flow of grain.

\section{PREFERRED CITATION:}

Burton, Mark. Barge Traffic Disruptions and Their Effects on Shipping Costs in Agricultural Freight Corridors. University of Tennessee, Knoxville. December 2019. Web. <http://dx.doi.org/10.9752/TS250.12-2019>

Photo credit: USDA

USDA is an equal opportunity provider, employer, and lender. 